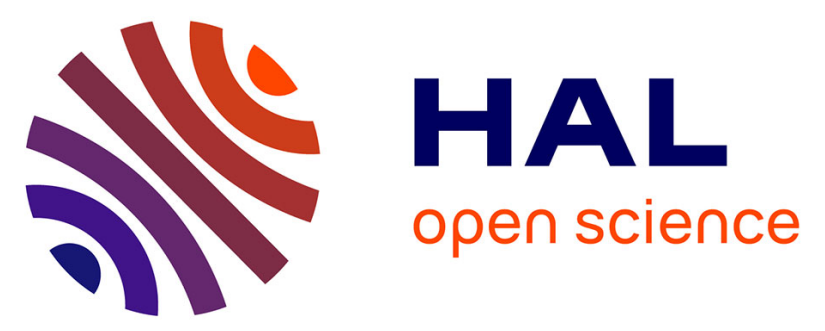

\title{
Assessment of Solute Transfer Between Static and Dynamic Water During Percolation Through a Solid Leach Bed in Dry Batch Anaerobic Digestion Processes
} Anil Shewani, Pierre Horgue, Sébastien Pommier, Gérald Debenest, Xavier Lefebvre, Sophie Decremps, Etienne Paul

\section{To cite this version:}

Anil Shewani, Pierre Horgue, Sébastien Pommier, Gérald Debenest, Xavier Lefebvre, et al.. Assessment of Solute Transfer Between Static and Dynamic Water During Percolation Through a Solid Leach Bed in Dry Batch Anaerobic Digestion Processes. Waste and Biomass Valorization, 2018, 9 (11), pp.2081-2089. 10.1007/s12649-017-0011-1 . hal-01795178

\section{HAL Id: hal-01795178 \\ https://hal.science/hal-01795178}

Submitted on 18 May 2018

HAL is a multi-disciplinary open access archive for the deposit and dissemination of scientific research documents, whether they are published or not. The documents may come from teaching and research institutions in France or abroad, or from public or private research centers.
L'archive ouverte pluridisciplinaire HAL, est destinée au dépôt et à la diffusion de documents scientifiques de niveau recherche, publiés ou non, émanant des établissements d'enseignement et de recherche français ou étrangers, des laboratoires publics ou privés. 


\section{OATAO \\ Open Archive Toulouse Archive Ouverte}

\section{Open Archive TOULOUSE Archive Ouverte (OATAO)}

OATAO is an open access repository that collects the work of Toulouse researchers and makes it freely available over the web where possible.

This is an author-deposited version published in : http://oatao.univ-toulouse.fr/ Eprints ID : 19831

To link to this article : DOI:10.1007/s12649-017-0011-1

URL : https://doi.org/10.1007/s12649-017-0011-1

To cite this version : Shewani, Anil and Horgue, Pierre $\leftrightarrows$ and Pommier, Sébastien and Debenest, Gérald $\leftrightarrows$ and Lefebvre, Xavier and Decremps, Sophie and Paul, Etienne Assessment of Solute Transfer Between Static and Dynamic Water During Percolation Through a Solid Leach Bed in Dry Batch Anaerobic Digestion Processes. (2017) Waste and Biomass Valorization, vol. 9 ( $\left.\mathrm{n}^{\circ} 47\right)$. pp. 1-9. ISSN 1877-2641

Any correspondence concerning this service should be sent to the repository administrator: staff-oatao@,listes-diff.inp-toulouse.fr 


\title{
Assessment of Solute Transfer Between Static and Dynamic Water During Percolation Through a Solid Leach Bed in Dry Batch Anaerobic Digestion Processes
}

\author{
Anil Shewani $^{1,4} \cdot$ Pierre Horgue $^{2,3} \cdot$ Sébastien Pommier ${ }^{1} \cdot$ Gérald Debenest $^{2,3,5}$. \\ Xavier Lefebvre $^{1} \cdot$ Sophie Decremps $^{4} \cdot$ Etienne Paul $^{1,5}$
}

\begin{abstract}
The aim of this work was to characterize solute transfer between static and dynamic water during percolation through a solid leach bed reactor. A new experimental procedure was set up to measure the solute exchange rate between macro-and micro-porosity. Tracer tests were performed in closed-circuit recirculation experiments. The water behavior was modeled by a multiphase flow model in a double porosity medium using a previously published methodology. The solute exchange rate between static and
\end{abstract}

dynamic water was described by first-order kinetics. The methodology was applied to wheat straw and solid cow manure beds. The solute exchange rate $\left(h_{s}\right.$ was 0.054 and $0.324 \mathrm{~h}^{-1}$ ) for wheat straw and solid cow manure, respectively. The measured data was used to improve the prediction capacity of a CFD tool. The results of this work could be used to develop appropriate leachate recirculation strategies to optimize full-scale dry batch anaerobic digestion processes.

Gérald Debenest

debenest@imft.fr

$\triangle$ Etienne Paul

paul@insa-toulouse.fr

1 LISBP, Université de Toulouse, CNRS, INRA, INSA,

Toulouse, 135 Avenue de Rangueil, 31077 Toulouse, France

2 Université de Toulouse; INPT, UPS; IMFT

(Institut de Mécanique des Fluides de Toulouse),

Allée Camille Soula 31400 Toulouse, France

3 CNRS, IMFT, 31400 Toulouse, France

4 Engie INEO, 10 Impasse André Marestan BP 44795, 31047 Toulouse Cedex 01, France

5 Département GPE, INSA Toulouse, 135 Avenue de Rangueil, 31077 Toulouse Cedex 4, France 


\section{Graphical Abstract}

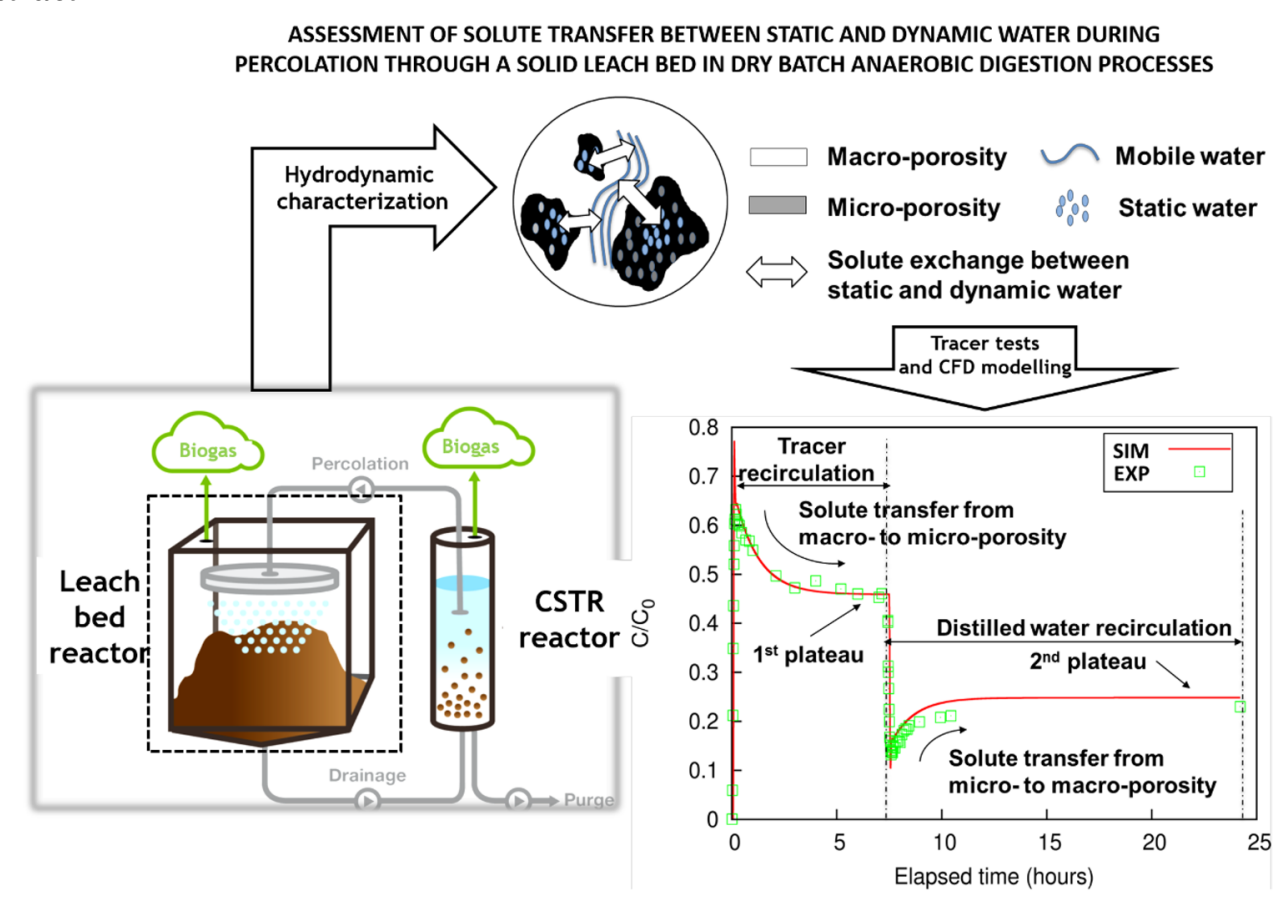

Keywords Dry batch anaerobic digestion - Double porosity $\cdot$ Leachate percolation $\cdot$ Solute exchange

\section{Introduction}

Dry batch anaerobic digestion is a promising and attractive method for treating agricultural solid waste so as to recover both energy and nutrients. In this type of technologies, agricultural solid wastes such as solid animal manure can supply a large fraction of biodegradable substrate for conversion into energy and can also be used as soil fertilizer $[17,21]$.

More and more on-farm dry batch digestion processes are being implemented because of their advantages: reactor design, operation at low water content, technical simplicity and easy solid waste handling [14, 15]. Water is one of the key elements of the dry digestion processes. When the water content is low and not appropriately distributed in the reactive media, long degradation times and unused biodegradation fractions are frequently reported in a solid leach bed $[15,21]$. Moreover, high organic loads in solid leach bed reactors can lead to bioprocess failure and a drop in the methane productivity because inhibiting molecules, such as volatile fatty acids (VFAs), $\mathrm{H}_{2}$ or $\mathrm{NH}_{4}^{+}$, can accumulate in the system [14]. With appropriate leachate recirculation strategies: injection volume, flow rate, injection geometry and frequencies $[3,16,22,23]$, spreading of the resulting homogeneous percolate improves the transport of microorganisms and nutrients towards the biodegradable fraction,

and consequently enhances substrate hydrolysis [8, 24, 27]. Therefore, water distribution between static and dynamic water during percolation needs to be measured [22].

Leachate spreading helps the dilution and transport of intermediate metabolites via the liquid phase and also allows them to be washed out of the system [25]. However, there is very little research in the literature that focuses on solute wash-out from the solid bed through the percolate during flow process for dry batch-operated percolation reactors. Recently, André et al. [2] studied changes in physical properties and solute exchange between mobile and stagnant water during the dry batch anaerobic digestion of a $60 \mathrm{~L}$ solid cattle manure bed in saturated conditions. The scientific effort in the present work focuses on understanding the balance between the production of intermediate metabolites during the degradation process and their wash-out from the system. Hydrolysis takes place in the micro-porosity of the solid waste [19]. On the one hand, it is important to understand which percolation conditions during the degradation process could favor the transfer of soluble compounds from mobile water to the static water near the biodegradable fraction of solid waste in order to enhance hydrolysis. On the other hand, it is also essential to identify appropriate percolation conditions, which could help control the accumulation of solutes and their washout through the dynamic water. Therefore, solute transfer between static and dynamic water during the percolation and drainage process needs to be investigated.

Characterization of solute transfer with exchange between micro and macro-porosity has already been 
reported in the fields of geophysics, geochemistry and soil science. A large body of scientific work on soil porous media is available. Gaudet et al. [9], Bond et Wierenga [6] and Gvirtzman et al. [11] investigated solute transport with solute exchange between mobile and immobile water by performing tracer tests in sand and sediment samples. Solute exchange between both mobile and static waters was modeled using first-order kinetics. They concluded that a dual-porosity modeling approach could be used in a wide range of heterogeneously structured soils in order to characterize solute transport. Nevertheless, little research has focused on solute transfer characterization for solid waste structures. Bendz and Singh [4] studied lithium transport, performing tracer tests in municipal solid waste conceptualized as a triple porosity media. Solute mass exchange rate between the domains was modeled with first-order kinetics, similarly to what has been done in other works for non-equilibrium transport models [6, 10]. Recently, André et al. [2] performed tracer tests in saturated conditions through a solid cattle manure bed to quantify non-uniform water flow and solute exchange between mobile and stagnant water during dry batch anaerobic digestion. Nevertheless, the scope of their work was not sufficient to identify solute exchange between static and dynamic water in percolation conditions. Their modeling approach permitted the best-fitting values of the model parameters to be identified for a given flow injection condition, by adjusting to one or several data sets of outflow breakthrough curves. Hence, the model parameter values were not measured experimentally and more reliable experimental approaches should be developed to assess solute transfer during the percolation process. Recently, Liu et al. [18] performed a crossed experimental and modeling study on dual permeability structures in landfills. Using Gas pressure dropping test (GPDT) they investigate the gas breakthrough curves varying initial pressures, moisture contents and degradation phases to quantify the gas preferential flow effect.

The aim of this work was to study solute transfer between the static and the dynamic water during percolation and drainage processes for highly heterogeneous porous media such as solid agricultural wastes. A reliable methodology is proposed for identifying solute transfer by performing labscale experiments. The main hydrodynamic parameters of the bed materials were measured using a previously published procedure [22]. Then, closed-circuit tracer tests were performed in unsaturated (percolation) conditions. Solute convective transport was modeled using a multiphase flow model considering the solid waste as a double porous medium. Solute exchange between static and dynamic water was modeled using first-order kinetics. Numerical simulations were used to identify solute exchange rates and predict experimental tracer concentration.

\section{Materials and Methods}

\section{Solid Waste Characterization}

Solid cow manure and wheat straw samples came from an experimental farm of the French National Polytechnic Institute located close to Toulouse (Midi-Pyrénées, France). Samples were rapidly stored at $4{ }^{\circ} \mathrm{C}$ to stop biological activity. A representative mass of $1 \mathrm{~kg}$ of each sample was shredded to $1 \mathrm{~cm}$ and then dried at $105^{\circ} \mathrm{C}$ for $24 \mathrm{~h}$ to measure the initial gravimetric water content. Initial characteristics of both solid leach beds are reported in Table 1 .

\section{Tracer Analysis}

Sodium acetate was chosen as the tracer molecule. Acetic acid was quantified in a gas chromatograph (GC) equipped with a flame ionization detector (FID) by injection of the supernatant with an internal standard (4:1 propan-2-ol, $10 \mathrm{~g} \mathrm{~L}^{-1}$ in sulfuric acid $1 \mathrm{~N}$ ) in a fused silica column (Ø $0.53 \mathrm{~mm} \times 50 \mathrm{~m}$-Poraplot Q CHROMPACK Varian Inc., Hansen way, Palo Alto, USA). Sodium ion $\left(\mathrm{Na}^{+}\right)$was analyzed by ionic chromatography on a $\mathrm{D} \times 120$ system (Dionex, Sunnyvale, USA) equipped with an AS9HC column (Dionex, Sunnyvale, USA).

\section{Experimental Setup}

The experiments were conducted in a laboratory scale percolation device similar to the percolation reactor used in a previous work [22]. The device is represented schematically in Fig. 1. The total working height of the leach beds was chosen as $0.4 \mathrm{~m}$, close to the device width, in order to minimize side-effects at the vessel walls [13]. The water was injected using a peristaltic pump and the input flow was equally distributed using an injector with 20 needles which divided the input flow into 20 equal injection flows distributed above the whole working surface. For all the experiments performed, the applied surface hydraulic loads (SHLs) ranged between 80 and $557 \mathrm{~L} \mathrm{~h}^{-1} \mathrm{~m}^{-2}$, corresponding to peristaltic pump flow rates between 10 and $71 \mathrm{~L} \mathrm{~h}^{-1}$. The leachate was recovered at the outflow through a plastic funnel that filled a $25 \mathrm{ml}$ beaker to ensure sufficient leachate volume for sampling. Injected water and leachate mass were monitored using a precision balance.

\section{Water Distribution}

The main hydrodynamic parameters of a leach bed (microporosity, macro-porosity, solid fraction, static and dynamic water and apparent permeability of flow process) were measured according to the procedure proposed in Shewani et al. [22] before tracer tests were performed. No 
Table 1 Initial solid leach bed characteristics for wheat straw and solid cow manure
Fig. 1 Schematic diagram of the closed-circuit experimental set up for tracer tests [22]

\begin{tabular}{lll}
\hline Initial characteristics & Wheat straw & Solid cow manure \\
\hline Solid bed total wet mass $\mathrm{kgWM}(\mathrm{kg})$ & $2.30 \pm 1 \%$ & $20.8 \pm 1 \%$ \\
Solid bed total dry mass $\mathrm{kgDM}(\mathrm{kg})$ & $2.20 \pm 1 \%$ & $6.10 \pm 1 \%$ \\
Initial gravimetric water content $\left(\mathrm{kgH}_{2} \mathrm{O} \mathrm{kgWM}^{-1}\right)$ & 0.043 & 0.706 \\
Apparent density $\left(\mathrm{kgWM} \mathrm{m}^{-3}\right)$ & 45.72 & 393.93 \\
Solid particles dry density ${ }^{\mathrm{a}}\left(\mathrm{kgDM} \mathrm{m}^{-3}\right)$ & 1.69 & 1.69 \\
Total height $(\mathrm{m})$ & $0.40 \pm 1 \mathrm{~cm}$ & $0.42 \pm 1 \mathrm{~cm}$ \\
Initial leach bed volume $(\mathrm{L})$ & $50.3 \pm 1.21$ & $52.8 \pm 1.21$ \\
Solid bed volume after water immersion and drainage ${ }^{\mathrm{b}} V_{T}(\mathrm{~L})$ & 43.4 & 49.0 \\
Solid fraction $\varphi_{s}^{\mathrm{b}}\left(\mathrm{m}^{3} \mathrm{~m}^{-3}\right)$ & 0.03 & 0.08 \\
Total porosity $\left(\varphi_{m}+\varphi_{M}\right)^{\mathrm{b}}\left(\mathrm{m}^{3} \mathrm{~m}^{-3}\right)$ & 0.97 & 0.92 \\
Micro-porosity $\left(\varphi_{m}\right) \mathrm{b}\left(\mathrm{m}^{3} \mathrm{~m}^{-3}\right)$ & 0.17 & 0.41 \\
Macro-porosity $\left(\varphi_{M}\right) \mathrm{b}\left(\mathrm{m}^{3} \mathrm{~m}^{-3}\right)$ & 0.80 & 0.51 \\
Volume of solid fraction ${ }^{\mathrm{b}} V_{s}(\mathrm{~L})$ & 1.32 & 3.63 \\
Volume of micro-pores ${ }^{\mathrm{b}} V_{m}(\mathrm{~L})$ & 7.10 & 20.3 \\
Volume of macro-pores ${ }^{\mathrm{b}} V_{M}(\mathrm{~L})$ & 34.9 & 25.1 \\
Dynamic water retention at $20 \mathrm{~L} \mathrm{~h}^{-1} \mathrm{~m}^{-2} \mathrm{~b}(\mathrm{~L})$ & 1.78 & 4.07 \\
\hline
\end{tabular}

${ }^{\mathrm{a}}$ Calculated as proposed by Agnew and Leonard [1] and previously used in Shewani et al. [22]

${ }^{\mathrm{b}}$ Measured according to the procedure proposed in Shewani et al. [22]

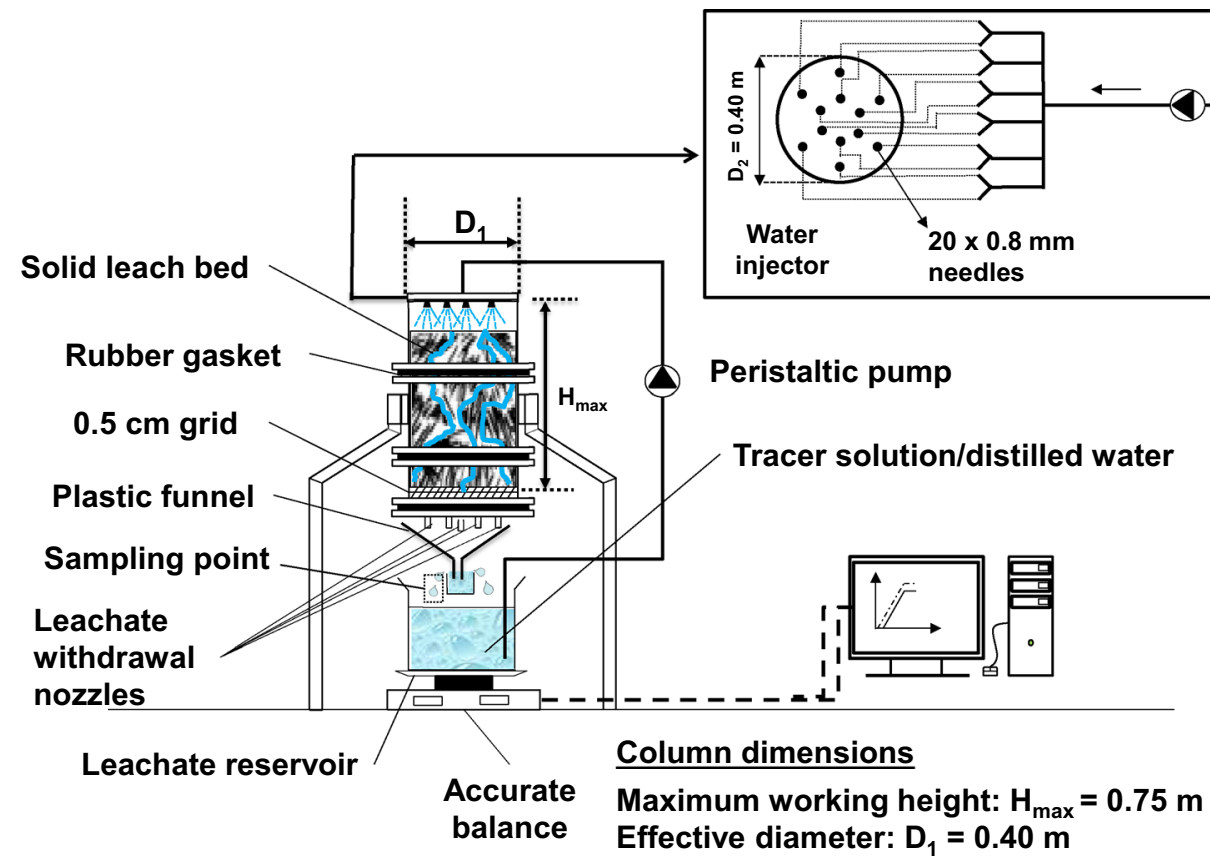

mechanical pretreatment was carried out for solid leach beds for any of the experiments. To assess the repeatability of the results, water distribution experiments were performed for three wheat straw and two solid cow manure beds. Only one leach bed of each solid waste was selected for the forthcoming tracer experiments. It was assumed that both leach beds remained at water holding capacity. These conditions were reached after several percolation and drainage cycles performed during the hydrodynamic characterization [22]. 


\section{Tracer Tests}

\section{Tracer Choice and Preparation}

To perform tracer monitoring through solid waste, the following conditions should be met $[3,5]$ :

- The tracer must not be present in the investigated medium.

- The contact time between the tracer and the digestion medium must be long enough to allow equilibrium to be reached between the phases and short enough to avoid degradation and/or physicochemical transformation of the tracer.

Rosqvist and Destouni [20] used lithium as a tracer to study solute transport through leachate in a solid waste sample from a landfill. Bollon et al. [5] used potassium iodide (KI) to measure diffusion coefficients in solidstate anaerobic digestate and Benbelkacem et al. [3] also used iodide ion monitoring to identify the macro-mixing of liquid and solid phases in high-solids digestion media. Recently, André et al. [2] used sodium chloride $(\mathrm{NaCl})$ at $0.1 \mathrm{M}$ to perform conservative tracer tests in solid cattle manure. In the present work, sodium acetate was chosen as the tracer. Both acetic acid and sodium are present during the biodegradation process and they are easily detectable. Acetic acid (HAc) concentration was traced for wheat straw. Because of the high content of microorganisms in solid cow manure, an eventual production or consumption of HAc could occur during tracer tests and interfere with tracer concentration measurements. Consequently, for solid cow manure beds, sodium $\left(\mathrm{Na}^{+}\right)$was monitored.

Prior to tracer tests, residual tracer concentration was naturally present in the leach beds during the water distribution measurements. The tracer concentration was monitored during these experiments and a high concentration of tracer was chosen (ranging between 0.7 and $0.9 \mathrm{~mol} \mathrm{~L}^{-1}$ ) to ensure a large gap between the tracer concentration and the residual acetic acid and sodium concentrations present in the leach bed before the start of the tracer tests. Biological activity could also occur during experiments but it was expected to be minimized for the following reasons:

- A large amount of water was percolated in order to wash out the targeted molecule (sodium or acetic acid).

- A high pH (9.2) was measured in the tracer solution and potentially neutralized any aerobic biological activity during the experiments.

- Each experiment was of short duration (35 h)

In spite of these considerations, the mass balance on acetate was not satisfying enough for the tests on manure.
Sodium was conservative and thus chosen as the tracer solute for all experiments on this substrate.

The initial conditions of tracer experiments for both solid leach beds are summarized in Table 2 (flow rate, tracer concentration and injected volumes). Tracer experiments were performed for both wheat straw and solid cow manure leach beds.

\section{Closed-Circuit Experiments}

Two different reservoir volumes of tracer solution or distilled water were chosen: $5 \mathrm{~L}$ for wheat straw and $10 \mathrm{~L}$ for solid cow manure. The injection flow rate was set to 20 $\mathrm{L} \mathrm{h}^{-1}$, corresponding to a surface hydraulic load $(S H L)$ of $160 \mathrm{~L} \mathrm{~h}^{-1} \mathrm{~m}^{-2}$ for both leach beds. This value of the surface hydraulic load was in the range of those observed in full-scale dry batch AD processes. The tracer or distilled water was injected into the system and recycled until a concentration equilibrium state was reached (approximately $17 \mathrm{~h}$ were required to reach a stable and identical tracer concentration in both static and dynamic waters). The sampling frequency was adapted to the leachate flow. Once steady-state had been reached, the leachate reservoir was instantaneously replaced by a distilled water reservoir (same liquid volume) and the recirculation continued until a new equilibrium state was reached. The same sampling procedure was carried out for distilled water recirculation. The sampled volume, approximately $300 \mathrm{~mL}$, was less than $6 \%$ of the total volume of tracer solution or distilled water and was taken into account in the tracer mass conservation calculation.

\section{Mathematical Modeling}

In a previous work [22], the hydrodynamic characterization during percolation was assessed using a "double porosity" approach, making a distinction between mobile water flowing through the larger pores (this fraction of the void space of the waste is called the macro-porosity) and static water trapped in the smaller pores (fraction

Table 2 Initial conditions of wheat straw and solid cow manure leach beds in tracer tests for closed-circuit experiments

\begin{tabular}{lll}
\hline Closed-circuit experiments & Wheat straw & Solid cow manure \\
\hline Tracer monitored & Acetic acid (HAc) & Sodium $\left(\mathrm{Na}^{+}\right)$ \\
$Q\left(\mathrm{~L} \mathrm{~h}^{-1}\right)$ & 20.0 & 20.0 \\
$S H L\left(\mathrm{~L} \mathrm{~h}^{-1} \mathrm{~m}^{-2}\right)$ & 160 & 160 \\
$C_{0}\left(\mathrm{~g} \mathrm{~L}^{-1}\right)$ & $39.1 \pm 12 \%$ & $14.7 \pm 0.7 \%$ \\
$V_{0}(\mathrm{~L})$ & $5.00 \pm 0.11$ & $10.0 \pm 0.11$ \\
\hline
\end{tabular}


called micro-porosity). Following the same approach, it was necessary to define two concentrations for any solute in the mathematical model: $C_{M}$ (for macro-porosity) and $C_{m}$ (for micro-porosity). The conservation of these two concentrations is given, respectively, by

$\varphi_{M} S_{M} \frac{\partial C_{M}}{\partial t}+\nabla \times\left(C_{M} U_{L}\right)=\nabla \times\left(\varphi_{M} S_{M} D \nabla C_{M}\right)+h_{s}\left(C_{M}-C_{m}\right)$

$\varphi_{m} S_{m} \frac{\partial C_{m}}{\partial t}=-h_{s}\left(C_{M}-C_{m}\right)$

where $\varphi_{M}$ and $S_{M}$ are the macro-porosity $\left(\mathrm{m}^{3} \mathrm{~m}^{-3}\right)$ and macro-saturation $\left(\mathrm{m}^{3}\right.$ of water per $\mathrm{m}^{3}$ of macro-porosity) values, respectively; $\varphi_{m}$ and $S_{m}$ are the micro-porosity $\left(\mathrm{m}^{3} \mathrm{~m}^{-3}\right)$ and micro-saturation $\left(\mathrm{m}^{3}\right.$ of water by $\mathrm{m}^{3}$ of macro-porosity) values, respectively; $C_{M}$ and $C_{m}\left(\mathrm{~kg} \mathrm{~m}^{-3}\right)$ are the solute concentrations in dynamic (macro) and static (micro) water, respectively. $D$ is the molecular diffusion coefficient of the solute in the water $\left(\mathrm{m}^{2} \mathrm{~s}^{-1}\right)$. It was neglected in the conservation equation of micro-concentration as it was assumed that the static water was a noncontinuous phase, the water being trapped in unconnected areas. The molecular diffusion that occurred between macro- and micro-concentration was taken into account via the exchange term $h_{s}\left(C_{M}-C_{m}\right)$ where $h_{s}\left(\mathrm{~h}^{-1}\right)$ is the solute exchange rate between micro- and macro-porosity. Note that the exchange rate depends directly on the interfacial area between mobile and static water. However in this work, mobile water had a small macro-saturation range (between 5 and $15 \%$ of the macro-porosity) and we assumed that the exchange rate could be considered as a constant, depending on the substrate.

We assumed that the injection was homogeneous at the inlet and that the experimental set-up could be modeled using a 1D approach [23]. The numerical modeling tool for multiphase flow in porous media [12] was extended to the transport of macro and micro-concentrations of a passive solute. For each time-step, the numerical method based on the IMPES method solved (i) the saturation equations, (ii) the concentration equations and (iii) the pressure equation. More detailed information is available in Horgue et al. [12] and in the supplementary data of Shewani et al. [22] for the double porosity approach.

\section{Results and Discussion}

\section{Water Distribution: Hydrodynamic Characterization}

The main hydrodynamic parameters of each solid leach bed were measured according to the methodology described in a previous study [22]. Macro- and micro-pore volumes and the solid fraction volume were estimated after the water holding capacity had been reached. Values are reported in Table 1. For the solid cow manure, the micro- and macroporosity values were similar to those obtained in Shewani et al. [22] (41 and 51\% for micro- and macro-porosity, respectively). Micro- and macro-porosity fractions made up 44 and $56 \%$ of the total porosity. These fractions were similar to those proposed by André et al. [2]. They reported a fraction of stagnant water in $38 \%$ of the total porosity and a fast flow through macro-pores in $62 \%$ of the total porosity.

The porous structure of wheat straw was significantly different, with lower micro-porosity (17\%) and higher macro-porosity (80\%). This could be explained by the fraction of feces in solid cow manure. Cow feces present high micro-porosity and high capillary forces, leading to higher water retention capacity.

For the two-phase flow parameters, the dynamic water volume in the waste (the macro-saturation) was correlated to the flow rate using a classical approach [7]. The apparent permeability $K_{L}\left(\mathrm{~m}^{2}\right)$, which was the product of intrinsic permeability $K_{Z}\left(\mathrm{~m}^{2}\right)$ and the relative permeability $k_{r, L}$, was determined for each solid waste,

$K_{L}\left(S_{M}\right)=K_{z} \times k_{r, L}\left(S_{M}\right)=K_{z}\left(S_{M}\right)^{p}$

where $S_{M}$ is the macro-saturation value and $p$ is the empirical model parameter, varying between 0.1 and 10 . The z-axis intrinsic permeability $\left(K_{Z}\right)$ of solid waste was determined for wheat straw $\left(2.9 \times 10^{-9} \mathrm{~m}^{2}\right)$ and solid cow manure $\left(3.3 \times 10^{-10} \mathrm{~m}^{2}\right)$ as was the empirical model parameter $(p), 2.2$ for wheat straw and 3.6 for solid cow manure. The intrinsic permeability of solid waste $K_{Z}\left(\mathrm{~m}^{2}\right)$ could be expressed as hydraulic conductivity $K_{w}$, defined in terms of fluid velocity $\left(\mathrm{m} \mathrm{s}^{-1}\right)$, which gave values of $2.84 \times 10^{-2}$ and $3.24 \times 10^{-3} \mathrm{~m} \mathrm{~s}^{-1}$ for wheat straw and solid cow manure, respectively. André et al. [2] measured hydraulic conductivity values under saturated conditions for a solid cattle manure bed before and during the dry batch AD. They reported a hydraulic conductivity value of $1.7 \times 10^{-3} \mathrm{~m} \mathrm{~s}^{-1}$ before the dry batch AD for solid cattle manure. Recently, Wedwitschka et al. [26] studied and characterized several bed and structural materials at different compaction levels in order to evaluate their percolation capacity during dry batch AD processes. They reported a lower hydraulic conductivity value for solid cattle manure $\left(2.48 \times 10^{-5} \mathrm{~m} \mathrm{~s}^{-1}\right)$ and showed that hydraulic conductivity of solid cattle manure increased almost eight times when mixed with $3 \%$ of straw and $10 \%$ woodchips (wet mass basis). For wheat straw bed, Wedwischka et al. [26] measured a hydraulic conductivity value of $1 \times 10^{-4} \mathrm{~m} \mathrm{~s}^{-1}$ in natural conditions (without any forced compaction). The difference between the values of the literature data and those presented in this work could be explained by the nature of the solid waste, 
the solid stack construction, geometry and the injection conditions (saturated or unsaturated in water). Globally, the values estimated in Shewani et al. [22] and those of the present work are consistent with the data available in the literature even though the methodologies and injection conditions are different from the ones presented in this work.

\section{Observation of Solute Transfer Between Micro- and Macro-Porosity}

Once the hydraulic equilibrium had been reached, solute transfer between static and dynamic water was observed for a tracer or distilled water injection. Figure 2 presents the evolution of the relative tracer concentration $\left(C / C_{0}\right)$ with time for both wheat straw (Fig. 2a) and solid cow manure (Fig. 2b) during closed-circuit experiments. $C_{0}$ is the initial tracer concentration injected in the system as measured in the reservoir.
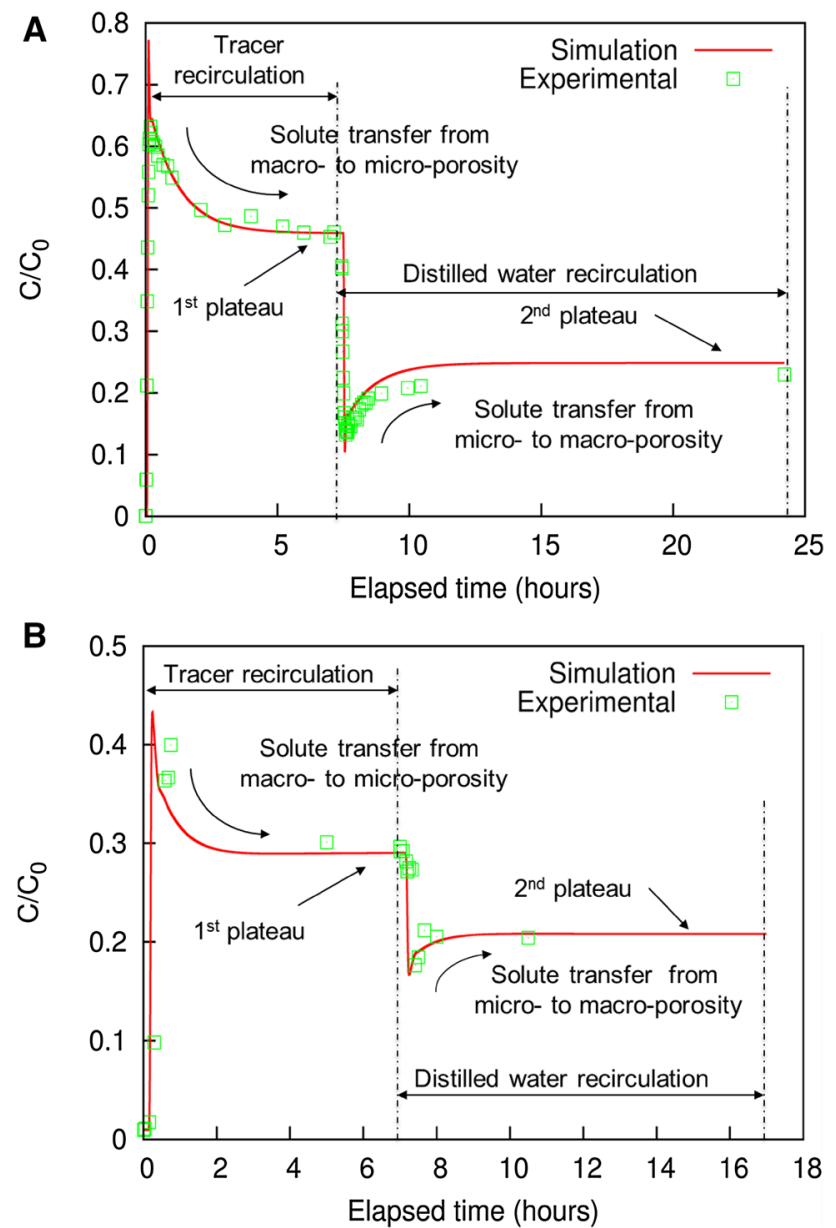

Fig. 2 Evolution of the tracer concentration versus time of closedcircuit experiments for $\mathbf{a}$ wheat straw (Acetic Acid) and $\mathbf{b}$ solid cow manure (Sodium). Squares represent experimental values and continuous lines represent simulated data
At the beginning of the experiment, the tracer concentration increased rapidly for a few minutes until a peak was reached. Then, the concentration progressively decreased until a plateau was obtained after $7 \mathrm{~h}$ of continuous recirculation. This behavior was related to the difference between the residence time of the mobile water and the time required to reach the equilibrium between microand macro-concentration. The solute transfer was slower than the convective transport of the mobile phase (water) through the macro-porosity. That explained why the equilibrium state was not reached directly and a concentration peak, which value was greater than final equilibrium but lower than the initial concentration of the reservoir, was measured at the outlet of the waste. The value of this peak and the equilibrium dynamics were used to obtain the transfer coefficient. Afterwards, the leachate from the reservoir was replaced with the same volume of distilled water, without stopping the injection. Then, using the same procedure, the distilled water volume was recycled in the system and similar behavior was observed, leading to a 2nd stabilized plateau that was lower than the first one.

\section{Tracer Tests: Validation of Tracer Mass Conservation}

A tracer mass conservation balance was performed for the two closed-circuit experiments, with wheat straw and solid cattle manure beds. The objective was to ensure that the hydrodynamics characterization was correct in terms of water volume. Since the tank capacity and mobile water volume were measured directly during the experiment, this preliminary step ensured that the micro-porosity deduced from previous experiments was correct. The mass conservation balance was performed for the two equilibrium states: the first one after the tracer was injected into the leach bed (1st plateau in Fig. 2a, b) and the second one after the leach bed had been washed out with distilled water (2nd plateau in Fig. 2a, b). The results are summarized in Table 3. The relative error $\varepsilon(\%)$ between the theoretical (calculated) and measured concentration of acetic acid at the equilibrium state was $21.9 \%$ for the first plateau and $12.8 \%$ for the second plateau in the case of the wheat straw. The relative error in terms of mass conservation for solid cow manure was 1.9 and $0.6 \%$ respectively.

For the solid cattle manure, the micro-porosity of the waste (i.e. the water holding capacity) was determined experimentally and showed good agreement with the theoretical values for both steps (1st and 2 nd plateau). However, in the case of the wheat straw, the mass conservation was not ensured, which can be explained by the fact that the static water present in the waste was not completely involved in the tracer transfer between macro- and microporosity. For the following, we consider that only $61.4 \%$ of the micro-porosity is involved in the tracer transfer 
Table 3 Acetic acid (HAc) and sodium $\left(\mathrm{Na}^{+}\right)$mass balances for closed-circuit experiments

\begin{tabular}{|c|c|c|c|c|c|c|}
\hline \multirow{2}{*}{$\begin{array}{l}\text { Tracer mass } \\
\text { conservation }\end{array}$} & \multicolumn{3}{|l|}{ Wheat straw } & \multicolumn{3}{|c|}{ Solid cow manure } \\
\hline & $\begin{array}{l}\text { Calculated } \\
\left(\text { mgHAc L }^{-1}\right)\end{array}$ & $\begin{array}{l}\text { Measured } \\
\left(\text { mgHAc L }^{-1}\right)\end{array}$ & $\varepsilon(\%)$ & $\begin{array}{l}\text { Calculated } \\
\left(\mathrm{mgNa}^{+} \mathrm{L}^{-1}\right)\end{array}$ & $\begin{array}{l}\text { Measured } \\
\left(\mathrm{mgNa}^{+} \mathrm{L}^{-1}\right)\end{array}$ & $\varepsilon(\%)$ \\
\hline Initial pulse & - & 23 & - & - & 142 & - \\
\hline 1st plateau & 14,048 & 17,984 & +21.9 & 4524 & 4438 & 1.90 \\
\hline Initial wash & & & & & 4369 & - \\
\hline 2nd plateau & 10,145 & 8989 & -12.8 & 3079 & 3060 & 0.60 \\
\hline
\end{tabular}

$\left(\varphi_{m}=10.08 \%\right.$ instead of $\left.16.42 \%\right)$ which gives a relative error of $+2.62 \%$ for the first plateau and $+2.76 \%$ for the second plateau.

\section{Closed-Circuit Experiments: Estimation of Solute Exchange Rate $\left(h_{s}\right)$}

Numerical simulations of the closed-circuit experiments were performed to estimate the solute exchange rate coefficient $\left(h_{s}\right)$ for both solid bed materials. The simulated results are represented as continuous lines in Fig. 2a, b, which compare the computed concentration at the outlet of the bed with the experimental measurements. Modeling was performed using experimental parameters except for the micro-porosity of the wheat straw, which was changed to ensure mass conservation. Using numerical simulations, the optimal solute exchange rates between static and dynamic water $\left(h_{s}\right)$ were identified and had values of $0.054 \mathrm{~h}^{-1}$ for wheat straw and $0.324 \mathrm{~h}^{-1}$ for solid cow manure. In the case of the wheat straw, the simulation showed good agreement, capturing the stabilization process during both the tracer injection and washing steps.

Note that the numerical approach highlighted a high concentration peak of short duration at breakthrough time, which was not visible in the experimental measurements. This short-time behavior (i) is difficult to capture experimentally (as it would require a high frequency of measurements) and (ii) may be not experimentally present due to local waste heterogeneities (numerical simulations are "ideally" homogeneous). Except for this short-term effect, the exponential decay allowed the solute exchange rate to be precisely evaluated. In the case of solid cattle manure, the solute transfer was faster and did not permit the exponential decay to be captured correctly. However, the experimental points, in particular the minimum and maximum values, allowed the solute exchange rate to be evaluated for solid cow manure. It was six times faster than for wheat straw.

This could be explained by the difference of the ratio between micro-porosity and macro-porosity in the two solid wastes. The data reported in show that the ratios between micro- and macro-porosity for solid cow manure and wheat straw are 0.82 and 0.21 , respectively. Actually, when the micro- to macro-porosity ratio is higher (as for solid cow manure) the macro-saturation at a given flow rate is higher. So, for a given flow process at a constant surface hydraulic load, a larger amount of dynamic water will be in contact with the micro-pores $(1.78$ and $4.07 \mathrm{~L}$ measured dynamic water retention for wheat straw and solid cow manure, respectively, at $20 \mathrm{~L} \mathrm{~h}^{-1} \mathrm{~m}^{-2}$ ). Thus, the efficient "exchange surface" appears to be higher for solid cow manure. André et al. [2] modeled solute exchange between mobile and stagnant water, also using first-order kinetics, and reported solute exchange rate values ranging between 2.24 and $2.71 \mathrm{~h}^{-1}$ for solid cattle manure. Their values are higher than those estimated in this work. This could be due to the saturated conditions used for their experiments (macro-pores filled with water) for which the effective exchange surface between micro- and macro-porosity is maximized. No other data were found in the literature for solid cow manure. Further experimental work will be needed to measure the solute exchange rate for different injection conditions and thus to study the relationship between the macro-saturation and the exchange surface involved during solute transfer.

\section{Conclusions}

A reliable methodology was developed to assess solute transfer between static and dynamic water for leach bed reactors. The solute transfer rate depends on the ratio between micro- and macro-porosity, which defines the exchange surface and the solute wash-out efficiency. Future work should focus on applying the proposed methodology to study the influence of the exchange surface and leachate percolation strategies (injection volume, surface hydraulic load and frequency) on the solute exchange rate at different compaction levels. Knowing the exchange term coefficient will allow a better estimate in concentration levels, both in the micro- and macroporosities. Since there is a strong coupling between solute concentrations and reactivity (biodegradation is $\mathrm{pH}$ dependent for instance), this will also lead to a better modeling of the biological kinetics inside the leach bed. 
The outcome of this work can thus be used to develop appropriate leachate recirculation strategies to optimize full-scale dry batch anaerobic digestion processes.

Acknowledgements The authors thank "Région de Midi-Pyrénées", ADEME (French National Energy and Environment Agency) and Engie INEO for their financial support. They acknowledge E. Mengelle, M. Bounouba, D. Delagnes, and M. Mauret for their contributions, and Susan Becker for English proofreading.

\section{References}

1. Agnew, J.M., Leonard, J.J.: The physical properties of compost. Compost Sci. Util. 11, 238-264 (2003). doi:10.1080/10656 57X.2003.10702132

2. André, L., Durante, M., Pauss, A., Lespinard, O., Ribeiro, T., Lamy, E.: Quantifying physical structure changes and nonuniform water flow in cattle manure during dry anaerobic digestion process at lab scale: Implication for biogas production. Bioresour. Technol. 192, 660-669 (2015). doi:10.1016/j. biortech.2015.06.022

3. Benbelkacem, H., Garcia-Bernet, D., Bollon, J., Loisel, D., Bayard, R., Steyer, J.-P., Gourdon, R., Buffière, P., Escudié, R.: Liquid mixing and solid segregation in high-solid anaerobic digesters. Bioresour. Technol. 147, 387-394 (2013). doi:10.1016/j.biortech.2013.08.027

4. Bendz, D., Singh, V.P.: Solute transport under steady and transient conditions in biodegraded municipal solid waste. Water Resour. Res. 35, 2333-2345 (1999). doi:10.1029/199 9WR900132

5. Bollon, J., Benbelkacem, H., Gourdon, R., Buffière, P.: Measurement of diffusion coefficients in dry anaerobic digestion media. Chem. Eng. Sci. 89, 115-119 (2013). doi:10.1016/j. ces.2012.11.036

6. Bond, W.J., Wierenga, P.J.: Immobile water during solute transport in unsaturated sand columns. Water Resour. Res. 26, 24752481 (1990). doi:10.1029/WR026i010p02475

7. Brooks R, Corey T (1964) Hydraulic Properties Of Porous Media. Hydrology Papers, Colorado State University

8. El-Mashad, H.M., van Loon, W.K.P., Zeeman, G., Bot, G.P.A., Lettinga, G.: Effect of inoculum addition modes and leachate recirculation on anaerobic digestion of solid cattle manure in an accumulation system. Biosyst. Eng. 95, 245-254 (2006)

9. Gaudet, J.P., Jégat, H., Vachaud, G., Wierenga, P.J.: Solute transfer, with exchange between mobile and stagnant water, through unsaturated sand. Soil Sci. Soc. Am. J. 41, 665 (1977). doi:10.2136/sssaj1977.03615995004100040009x

10. Gerke, H.H., van Genuchten, M.T.: Evaluation of a firstorder water transfer term for variably saturated dual-porosity flow models. Water Resour. Res. 29, 1225-1238 (1993). doi:10.1029/92WR02467

11. Gvirtzman, H., Paldor, N., Magaritz, M., Bachmat, Y.: Mass exchange between mobile freshwater and immobile saline water in the unsaturated zone. Water Resour. Res. 24, 1638-1644 (1988). doi:10.1029/WR024i010p01638

12. Horgue, P., Soulaine, C., Franc, J., Guibert, R., Debenest, G.: An open-source toolbox for multiphase flow in porous media. Comput. Phys. Commun. 187, 217-226 (2015)
13. Huet, J., Druilhe, C., Trémier, A., Benoist, J.C., Debenest, G.: The impact of compaction, moisture content, particle size and type of bulking agent on initial physical properties of sludgebulking agent mixtures before composting. Bioresour. Technol. 114, 428-436 (2012). doi:10.1016/j.biortech.2012.03.031

14. Karthikeyan, O.P., Visvanathan, C.: Bio-energy recovery from high-solid organic substrates by dry anaerobic bio-conversion processes: a review. Rev. Environ. Sci. Biotechnol. 12, 257-284 (2013). doi:10.1007/s11157-012-9304-9

15. Kothari, R., Pandey, A.K., Kumar, S., Tyagi, V.V., Tyagi, S.K.: Different aspects of dry anaerobic digestion for bio-energy: An overview. Renew. Sustain. Energy Rev. 39, 174-195 (2014). doi:10.1016/j.rser.2014.07.011

16. Kusch, S., Oechsner, H., Jungbluth, T.: Effect of various leachate recirculation strategies on batch anaerobic digestion of solid substrates. Int. J. Environ. Waste Manag. 9, 69 (2012). doi:10.1504/ IJEWM.2012.044161

17. Kusch, S., Schäfer, W., Kranert, M.: Dry Digestion of Organic Residues. InTech, Rijeka (2011)

18. Liu, L., Xue, Q., Wan, Y., Tian, Y.: Evaluation of dual permeability of gas flow in municipal solid waste: experiment and modeling. Environ. Prog. Sust. Energy 35(1), 41-47 (2016)

19. Pommier, S., Chenu, D., Quintard, M., Lefebvre, X.: A logistic model for the prediction of the influence of water on the solid waste methanization in landfills. Biotechnol. Bioeng. 97, 473482 (2007). doi:10.1002/bit.21241

20. Rosqvist, H., Destouni, G., Solute transport through preferential pathways in municipal solid waste. J. Contam. Hydrol. 46, 39-60 (2000). doi:10.1016/S0169-7722(00)00127-3

21. Schäfer, W., Lehto, M., Teye, F.: Dry anaerobic digestion of organic residues on-farm-a feasibility study (Report No. 2). Nordic Association of Agricultural Scientists. (2006)

22. Shewani, A., Horgue, P., Pommier, S., Debenest, G., Lefebvre, X., Gandon, E., Paul, E.: Assessment of percolation through a solid leach bed in dry batch anaerobic digestion processes. Bioresour. Technol. 178, 209-216 (2015). doi:10.1016/j. biortech.2014.10.017

23. Shewani, A., Horgue, P., Pommier, S., Debenest, G., Lefebvre, X., Gandon, E., Paul, E.: Using a reactive multiphase flow model to control VFAs accumulation in solid leach bed reactors. Presented at the 14th world congress on anaerobic digestion (AD14) 15-18th November 2015 Viña del mar (Chile)

24. Vavilin, V.A., Fernandez, B., Palatsi, J., Flotats, X.: Hydrolysis kinetics in anaerobic degradation of particulate organic material: an overview. Waste Manag. 28, 939-951 (2008). doi:10.1016/j. wasman.2007.03.028

25. Vavilin, V.A., Rytov, S.V., Lokshina, L.Y., Pavlostathis, S.G., Barlaz, M.A.: Distributed model of solid waste anaerobic digestion: effects of leachate recirculation and $\mathrm{pH}$ adjustment. Biotechnol. Bioeng. 81, 66-73 (2003). doi:10.1002/bit.10450

26. Wedwitschka, H., Jenson, E., Liebetrau, J.: Feedstock characterization and suitability assessment for dry anaerobic batch digestion. Chem. Eng. Technol. 1-9 (2016). doi:10.1002/ ceat. 201500413

27. Xie, S., Lawlor, P.G., Frost, J.P., Wu, G., Zhan, X.: Hydrolysis and acidification of grass silage in leaching bed reactors. Bioresour. Technol. 114, 406-413 (2012). doi:10.1016/j. biortech.2012.03.008 